\title{
Research on Optimization of Distribution Automation Terminal
}

\author{
Wanghailong ${ }^{1}$, Guozhimin², Zhengxinyi ${ }^{3}$, Yukun ${ }^{3 a}$
}

1.NARI Group Corporation (State Grid Electric Power Research Institute) Co., Ltd. Nanjing 211000, Jiangsu, China

2. State Grid Henan Electric Power Company Electric Power Research Institute, Zhengzhou 450052, Henan, China

3.College of Energy and Electrical Engineering, Hohai University, Nanjing 211100, China.

Email:akun.yu@vip.sina.com

Keywords: distribution automation terminal, whole life cycle, cost-benefit, optimal configuration Abstract: The mathematic model of distribution automation terminal configuration optimization is established based on the cost-benefit theory, taking the minimum area as the basic analysis unit, considering the balance of economy and reliability. The number and location of electrical distribution automation terminals are optimized by genetic algorithm. Under analysis IEEE RBTS-BUS 2 system, the results show that the power outage time and loss are significantly reduced after configuration, and the effectiveness of the method is verified.

\section{Introduction}

This article is based on the principle of distribution automation terminal configuration and the reliability evaluation method of distribution network, analyzes the reliability of the device, the total life cycle cost, and the continuous power outage loss calculation of various types of users in various regions first, and establishes a distribution automation terminal configuration model. GA algorithm is used to optimize the distribution system of IEEE RBTS BUS-2 to prove the practicability of the model.

\section{Analysis on the Influence of Distribution Automation Terminal Device on Power Supply Re- liability of Distribution Network}

1) Power Supply Reliability Index

In the optimization configuration calculation of this paper, assuming the reliability rate of the equipment itself in the distribution network is $100 \%$, the average system power outage duration SAIDI(unit: hour /(user * year)) is selected as an indicator to measure the reliability of the system $^{[5]}$ :

$$
\begin{aligned}
& \text { SAIDI }=\frac{\text { Total duration of user power outages }}{\text { Total number of users }} \\
& =\frac{\sum_{k=1}^{n} T_{k} N_{k}}{\sum_{k=1}^{n} N_{k}}
\end{aligned}
$$

$n$ represents the number of load points; $N_{k}$ represents the number of users at the $k$ load point; $T_{k}$ represents the duration of the power outage at the $k$ load point.

2) Average annual duration of power outages in minimum power supply areas

The fault time is divided into three types: fault location time $t_{1}$, fault isolation / transfer time $t_{2}$, and fault repair time $t_{3}$. According to the different mode of impact on load in other areas. 
The minimum area 1 from the power outage time is $\lambda_{11}$. When the minimum area 2 fails, the power outage time on the minimum area 1 depends on the equipment configured at the configuration point 1 . Set the power outage time between the minimum area 1 and the minimum area 2 is $\lambda_{12}$. The matrix should be as follows:

$$
\begin{aligned}
& Z_{t d}=\left[\begin{array}{lllll}
\gamma_{11} & \gamma_{12} & \gamma_{13} & \mathrm{~L} & \gamma_{1 m} \\
\gamma_{21} & \gamma_{22} & \gamma_{23} & \mathrm{~L} & \gamma_{1 m} \\
\gamma_{31} & \gamma_{32} & \gamma_{33} & \mathrm{~L} & \gamma_{2 m} \\
\mathrm{M} & \mathrm{M} & \mathrm{M} & \mathrm{O} & \gamma_{3 m} \\
\gamma_{m 1} & \gamma_{m 2} & \gamma_{m 3} & \mathrm{~K} & \gamma_{m m}
\end{array}\right] \\
& \gamma_{11}=\gamma_{22}=\gamma_{33}=\mathrm{K}=\gamma_{m m} \\
& \gamma_{k j}=\gamma_{j k}
\end{aligned}
$$

Set the minimum area $j$ front end configuration equipment, the minimum area fault location time required is $\zeta_{j}$, the fault isolation time is ${ }^{\sigma_{j}}$, and the minimum power supply area k fault repair time is $\tau_{k}$, and the fault time of different regions can be obtained. When the smallest region $k$ traverses the from end of the smallest region $j$, you can get for the line $k$ :

$$
\begin{aligned}
& \gamma_{k j}=\min \left(\zeta_{k+1}, \zeta_{k+2}, \zeta_{k+3}, \mathrm{~K}, \zeta_{j}\right) \\
& +\min \left(\sigma_{k+1}, \sigma_{k+2}, \sigma_{k+3}, \mathrm{~K}, \sigma_{j}\right)
\end{aligned}
$$

when a failure occurs in the minimum area, calculate power outage time:

$$
\gamma_{k k}=\max \left(\zeta_{k}, \zeta_{k+1}\right)+\max \left(\sigma_{k}, \sigma_{k+1}\right)+\tau_{k}
$$

Assume that the line failure rate is:

$$
\begin{aligned}
& \lambda^{\prime}=\left[\lambda_{1}, \lambda_{2}, \lambda_{3}, \mathrm{~K}, \lambda_{m}\right] \\
& \lambda_{k}=\left\{\begin{array}{c}
\bar{\lambda}_{J K L} \bullet l_{J K L}(\text { Line type is empty line }) \\
\bar{\lambda}_{\text {cable }} \bullet l_{\text {cable }}(\text { Line type is cable })
\end{array}\right.
\end{aligned}
$$

Among them, $\bar{\lambda}_{\text {cable }}$ represents the average failure rate of cable lines, $l_{\text {cable }}$ represents the length of cable lines, $\bar{\lambda}_{J K L}$ represents the average failure rate of overhead lines, and $l_{J K L}$ represents the length of overhead lines. The expected time $\bar{\gamma}$ of the line failure is:

$$
\bar{\gamma}=Z_{t d} \cdot \lambda^{T}=\left[\begin{array}{ccccc}
\gamma_{11} & \gamma_{12} & \gamma_{13} & \mathrm{~L} & \gamma_{1 m} \\
\gamma_{21} & \gamma_{22} & \gamma_{23} & \mathrm{~L} & \gamma_{1 m} \\
\gamma_{31} & \gamma_{32} & \gamma_{33} & \mathrm{~L} & \gamma_{2 m} \\
\mathrm{M} & \mathrm{M} & \mathrm{M} & \mathrm{O} & \gamma_{3 m} \\
\gamma_{m 1} & \gamma_{m 2} & \gamma_{m 3} & \mathrm{~K} & \gamma_{m m}
\end{array}\right] \cdot\left[\begin{array}{c}
\lambda_{1} \\
\lambda_{2} \\
\lambda \\
\mathrm{M} \\
\lambda_{m}
\end{array}\right]
$$

Let the number of loads $C_{\text {cont }}$ per minimum area be:

$$
C_{c o n t}=\left[\sum_{i=1}^{n_{1}} \eta_{1 i} \quad \sum_{i=1}^{n_{2}} \eta_{2 i} \sum_{i=1}^{n_{3}} \eta_{3 i} \mathrm{~K} \quad \sum_{i=1}^{n_{m}} \eta_{m i}\right]
$$

Among them, $n_{m}$ represents all nodes in the $m$ region; $\sum_{i=1}^{n_{m}} \eta_{m i}$ represents the total number of loads received in the $m$ minimum area, the feeder reliability should be:

$$
S A I D I=\frac{Z_{t d} \cdot \dot{\lambda}^{T} \cdot C_{c o n t}}{C_{\text {sum }}}
$$




\section{Analysis on the Impact of Distribution Automation Terminal Configuration on Distribution Network Economy}

1) Life cost cycle

$L C C=I C+M C+F C+S C$

IC represents the initial investment costs, $M C$ represents annual operating and maintenance costs, $F C$ represents the Failure costs, $S C$ represents the Scrap costs. The specific calculations are as follows:

(1) Equivalent conversion of costs

$y$ represents the interest rate, $\delta$ represents the present value, $X$ represents the final value, $Z$ represents the equivalent value, $D$ represents equivalent value ${ }^{[6]}$ :

$$
\begin{gathered}
Z=X(1+\delta)^{y} \Leftrightarrow X=\frac{Z}{(1+\delta)^{y}} \\
Z=D \frac{(1+\delta)^{y}-1}{\delta} \Leftrightarrow D=Z \frac{\delta}{(1+\delta)^{y}-1}
\end{gathered}
$$

The calculation results in a conversion between the following equivalent annual value and the present value:

$$
X=D \frac{(1+\delta)^{y}-1}{\delta(1+\delta)^{y}} \Leftrightarrow D=X \frac{\delta(1+\delta)^{y}}{(1+\delta)^{y}-1}
$$

(2) Initial cost of investment

$$
I C=w_{2} \cdot s_{2} \frac{\delta(1+\delta)^{y_{2}}}{(1+\delta)^{y_{2}}-1}+w_{3} \cdot s_{3} \frac{\delta(1+\delta)^{y_{3}}}{(1+\delta)^{y_{3}}-1}
$$

Among them, $s_{2} 、 s_{3} s_{p}$ represent the number of terminals of "two remote" and "three remote" respectively; $w_{2} 、 w_{3}$ represent the terminal investment cost of "two remote" and "three remote" respectively, $y_{2} 、 y_{3}$ represent the terminal service life of "two remote", "three remote" respectively.

(3) Annual operating maintenance costs of the installation:

Assuming that the annual operating maintenance cost of the device is proportional to the equivalent annual cost of the equipment investment cost, it is expressed as:

$M C=\partial \cdot I C$

Among this, $\partial$ represents maintenance costs for installations as a percentage of investment costs.

(4) Equipment failure repair expenses

Assuming that the reliability of the device itself is $100 \%$, it is the failure rate is 0 , the equipment failure maintenance costs are not counted.

(5) Equipment scrap costs

Indicated as follows:

$$
S C=(-\beta)\left(k_{2} s_{2} \frac{i}{(1+\delta)^{y_{2}}-1}+k_{3} s_{3} \frac{i}{(1+\delta)^{y_{3}}-1}\right)
$$

Among them, $\beta$ represents the net residual rate of the equipment. Since the residual value of the equipment is reversed from the investment cost, the scrap cost may be calculated as negative value, because of the model needs, we use $-\beta$ here.

2) Calculate the loss of power outage taking into account multiple users at different times

The network power outage loss can be represented by the following formula:

$W_{\text {Loss,ave }}^{\text {line }}$

$$
=\sum_{\text {line }=1}^{m_{l}} \sum_{k=1}^{m} \sum_{i=1}^{m_{c}} \underset{L_{\text {ave }, i}^{k}}{\stackrel{r}{\text { line }}} \cdot \stackrel{\mathrm{r}}{\text { line }}_{\text {Fault }, i}^{T} \cdot\left(a_{\text {con }, i} \bar{\gamma}_{k}^{\text {line }}+b_{\text {con }, i}\right)
$$


Among this, ${ }^{k}{ }_{\text {ave,i }}^{k, \text { line }}$ represents the average daily load of the $i$ user in the $k$ minimum power

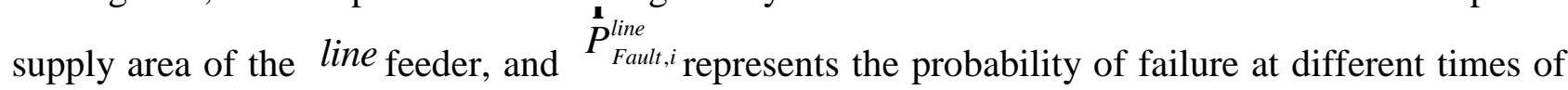
the line feeder. $\bar{\gamma}_{k}^{\text {line }}$ represents the annual power outage for the $k$ minimum power supply areas of the line feeder.

\section{mathematic model of distribution automation terminal optimal configuration}

1) Objective function

$$
\begin{aligned}
& \text { MinCF }=L C C+W_{\text {Loss ave }}^{\text {line }} \\
& \left.=L C C+\sum_{\text {line }=1}^{m_{l}} \sum_{k=1}^{m} \sum_{i=1}^{m_{c}} \stackrel{r}{L_{\text {ave }, i}} \stackrel{P_{\text {Fault }, i}{ }^{T} \cdot\left(a_{\text {con }, i} \bar{\gamma}_{k}^{\text {line }}+b_{\text {con }, i}\right)}{ }\right)
\end{aligned}
$$

Among this, $C F$ represents the total combined cost of cost-effectiveness.

2) Constraints

(1) Reliability constraints

$$
S A I D I \leq S A I D I_{0}
$$

Among them, SAIDI represents the average outage time of the system under a certain scheme configuration; $S A I D I_{0}$ represents the maximum average downtime .

(2) Set Point Constraints

Different devices may not be configured at the same node:

$$
x_{k}+y_{k} \leq 1
$$

Among them, if a "two remote" terminal is installed at a switch node, it may tcke $x_{k}=1$; if install "Three remote" terminal, it may take $y_{k}=1$.This formula means that only one "two remote" or "three remote" device can be installed at the same switch node;

(3) Node voltage constraints

$$
U_{k \text { min }} \leq U_{k} \leq U_{k \max }
$$

Where $U_{k}$ is the voltage of the node, $U_{k \max }$ and $U_{k \min }$ represent the upper and lower limits of the node voltage respectively.

(4) Position constraints

For a specific distribution network, the installation location of the distribution automation terminal device is related to the local special geographical location and surrounding terrain. There are also special construction requirements for special users and are also limited by the grid infrastructure.

\section{Optimizing Distribution Automation Terminal Configuration Flow Based on GA Algorithm}

(1) Coding Method

The encoding of different types of devices is as follows:

Table 1 Code Method for Distribution Automation Terminal Devices

\begin{tabular}{lccl}
\hline Chromosomal segment & code & $\begin{array}{c}\text { Descrip- } \\
\text { tion value }\end{array}$ & meaning \\
\hline & 00 & 0 & No devices configured \\
The first chromosome & 01 & 1 & Configure failure indicator \\
(segment switch) & 10 & 2 & Configure "Two Remote" Terminal \\
& 11 & 3 & Configure "three remote" Terminal \\
\hline
\end{tabular}


(2) Population generation and fitness function determination

The value of the fitness function should choose the reciprocal of the objective function:

Fitness $=\frac{H}{C F}$

Where $H$ represents the set constant.

(3) Selection, crossover, and variation operations

\section{Case analysis}

IEEE RBTS BUS-2 bus distribution system's ${ }^{[10]}$ structure is adopted. The nodes in the diagram is numbered for all the segmented switches and contact switches, The lines are numbered as follows ${ }^{[11-13]}$ :

Table 2 Line Number

\begin{tabular}{ccc|ccc}
\hline feeder & line & $\begin{array}{c}\text { Both ends } \\
\text { of the node }\end{array}$ & feeder & line & $\begin{array}{c}\text { Both ends of the } \\
\text { node }\end{array}$ \\
\hline 1 & 1 & $1-2$ & 3 & 8 & $6-7$ \\
1 & 2 & $2-3$ & 3 & 9 & $7-8$ \\
1 & 3 & $3-4$ & 3 & 10 & $8-14$ \\
1 & 4 & $4-12$ & 4 & 11 & $1-9$ \\
2 & 5 & $1-5$ & 4 & 12 & $9-10$ \\
2 & 6 & $5-13$ & 4 & 13 & $10-11$ \\
3 & 7 & $1-6$ & 4 & 14 & $11-15$ \\
\hline
\end{tabular}

The distribution of related electrical parameters and load parameters of the system is as follows[7-9] , assuming that the load remains unchanged throughout the planning cycle, the line impedance value is $0.27+j 0.347 \Omega / \mathrm{km}$.

Set the user's power outage probability at different points in time and the load data are in an open relationship:

$$
P_{\text {Fault }}(d)=\frac{\sqrt{\sum_{k=1}^{m} \sum_{i=1}^{m_{c}} L_{\text {ave }, i}^{k}(d)}}{\sum_{j=1}^{24} \sqrt{\sum_{k=1}^{m} \sum_{i=1}^{m_{c}} L_{a v e, i}^{k}(d)}}
$$

Among them, $P_{\text {Fault }}(d)$ represents the probability of failure of the user in the $d$ period and $L_{\text {ave }, d}$ represents the user's $d$ period load value. $L_{\text {ave }, i}^{k}(d)$ represents the load value of the $i$ user $d$ time in the $k$ minimum power supply area, and $P_{\text {Fault }}(d)$ represents the probability of failure in the feeder $d$ time. Obviously, there is $\sum_{j=1}^{24} P_{\text {Fault }}(d)=1$

Table 6 and Fig. 1 shows the results of the optimization of the configuration scheme and the corresponding indicators:

Table 3 Distribution Automation Equipment Optimal Configuration Scheme

\begin{tabular}{cc}
\hline "Two remote" position & "Three remote" position \\
\hline $4,6,9,11$ & $2,7,10$ \\
\hline
\end{tabular}




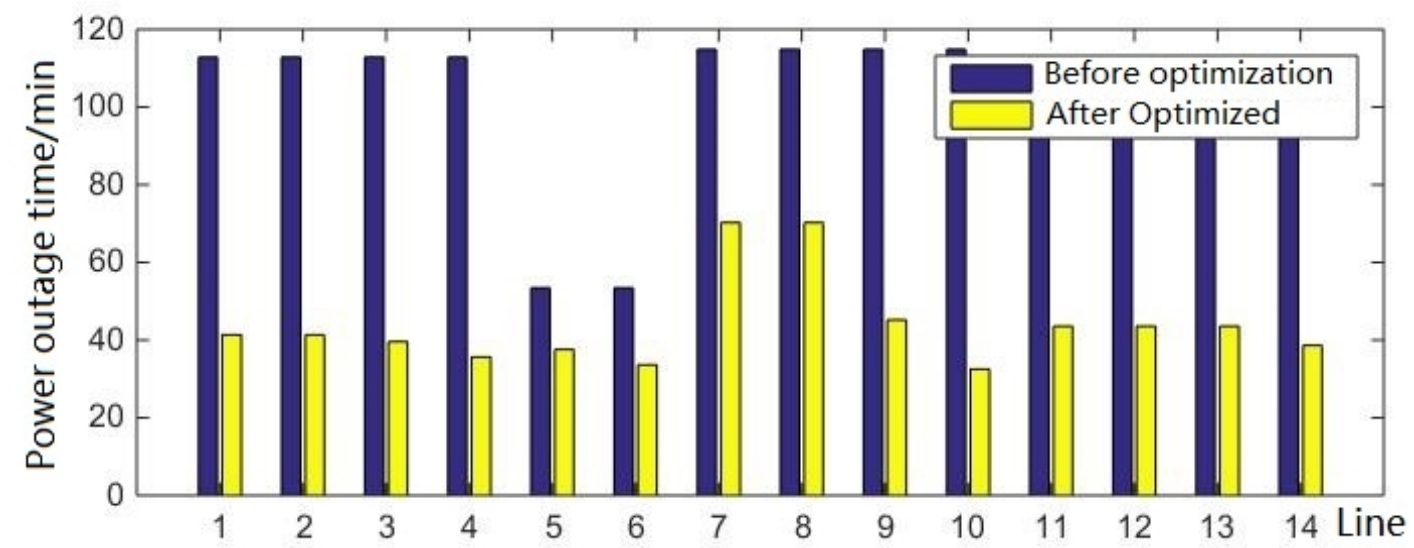

Fig. 1 Comparison of power outage time of each node load before and after optimization

\section{Conclusion}

The following conclusions were reached:

1) The optimization model distinguishes between different users, quantities, and power outage losses in various regions, and considers the influence of the presence of liaison on the time of load transfer, and optimizes the type, number, and location of distribution automation terminal devices.

2) The improved IEEE RBTS BUS-2 distribution system was optimized for distribution automation terminal equipment, the simulation results verified the feasibility of the optimized configuration plan. It can greatly reduce the time of power outage, reduce the loss of power outage, achieve the lowest comprehensive cost, and achieve the best reliability and economy.

\section{Acknowledgements}

This work was financially supported by Science and Technology Project of SGCC (Research on Operation Efficiency Monitoring and Analysis Technology of Distribution Network Assets Based on Big Data, WBS NO: 524608160055).

\section{References}

[1] Chentang. Distribution system and its automation technology[M].China Power Press, 2003.

[2] Linjikeng, Wangxudong, Zhengweihong, etc.Reliability Assessment of Switching Fault Distribution Network Based on Network-based Decimation[J].Power System Automation, 2009,33(9):32-36.

[3] Liu Jian, Li Chenghongli, Zhangzhihua. Distribution terminal configuration quantity planning in distribution automation system[ J] . Power System Automation, 2013, 37(12): 44-50.

[4] Wangxudong, Liangdong, Caobaoyi, etc.. Optimized Configuration of Sanyao Distribution Automation Terminal[J].Journal of Power Systems and Its Automation, 2016, 28(2): 36-42.

[5] Attari S K A, Bakhshipour M, Shakarami M, et al. A Novel Method Based on Teaching-Learning-Based Optimization for Recloser Placement with Load Model Consideration in Distribution System[J]. Indonesian Journal of Electrical Engineering and Computer Science, 2016, 2(1):1.

[6] Wangxiaobo. Life cycle cost model and application research of distribution network with reliability in mind[D]. Chongqing University, 2008. 
[7] Liulijun, Jiangxiubo, Caijinding, etc.. Segmental optimization of medium-voltage distribution network based on discrete particle groups for LCC[J].East China Power, 2014, 42(8): 1684-1690.

[8] Xubingyin, Litianyou, Xueyongduan.. Intelligent Distribution Network and Distribution Automation[J].Power System Automation, 2009(17): 38-41.

[9] Wangxiaoping, Caoliming.Genetic Algorithm: Theory, Application and Software Implementation[M] .Xi'an Jiaotong University Press, 2002.

[10]Allan R N, Billinton R, Sjarief I, et. A reliability test system for educational purposes-basic distribution system data and results[J]. IEEE Transactions on Power Systems, 2002, 6(2):813-820.

[11] Liu Jian, Li Chenghongli, Zhangzhihua. Distribution terminal configuration quantity planning in distribution automation system[J].Power System Automation, 2013, 37(12): 44-50.

[12]Naumann A, Komarnicki P, Powalko M, et al. Experience with PMUs in industrial distribution networks[C] Power and Energy Society General Meeting. IEEE, 2010:1-6.

[13] Wache M, Murray D C. Application of Synchrophasor Measurements for distribution networks[C] Power and Energy Society General Meeting. IEEE, 2011:1-4.

[14] Q/GDW 11184-2014 Distribution Automation Planning and Design Technical Guidelines[S] . Beijing: State Grid Company, 2013.

[15] Q/CSG 120101-2014 Distribution Network Automation Planning Guidelines[S]. Guangzhou:Southern Electric Grid Company, 2013. 